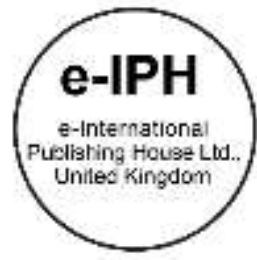

\title{
Sexual Harassment in Healthcare SMEs: Behaviours of medical practitioners and medical tourists
}

\author{
Nuraisyah Chua Abdullah¹, Herwina Rosnan², Norzayana Yusof3 \\ ${ }^{1}$ Faculty of Law, \\ ${ }^{2}$ Arshad Ayub Graduate Business School, \\ ${ }^{3}$ Centre for Postgraduate and Professional Studies, Faculty of Business and Administration, \\ Universiti Teknologi MARA, Shah Alam, 40450. Selangor. Malaysia
}

nuraisyahc@yahoo.com; nuraisyah@salam.uitm.edu.my; herwinaros@gmail.com; norzayana.yusof@yahoo.com Tel: +6019-6488348

\begin{abstract}
Healthcare SMEs are at risk of sexual harassment in the workplace due to several barriers resulting in medical professionals leaving the workforce and reduced productivity. The paper attempts to bridge the gap between the existing findings in general healthcare with medical tourism settings focusing on the medical tourists' behaviour in the destination country and the behaviour of medical practitioners in healthcare SMEs, who may be exposed to sexual harassment at workplace. Thus, this study urge for corrective actions in the medical tourism industry in ensuring the safety of medical tourists and practitioners in the rising demand for medical tourism.
\end{abstract}

Keywords: Sexual Harassment; Behaviour; Medical Practitioners; Medical Tourists

eISSN: 2398-42870 2018. The Authors. Published for AMER ABRA cE-Bsby e-International Publishing House, Ltd., UK. This is an open access article under the CC BYNC-ND license (http://creativecommons.org/licenses/by-nc-nd/4.0/). Peer-review under responsibility of AMER (Association of Malaysian Environment-Behaviour Researchers), ABRA (Association of Behavioural Researchers on Asians) and cE-Bs (Centre for Environment-Behaviour Studies), Faculty of Architecture, Planning \& Surveying, Universiti Teknologi MARA, Malaysia.

DOI: https://doi.org/10.21834/e-bpj.v3i8.1390

\subsection{Introduction}

Although cultural heritage is the central point for tourism (Azmi \& Ismail, 2016) medical tourism is a rising phenomenon that has attracted numerous scholars in academic and the professionals in the $21^{\text {st }}$ Century. It is a business activity that falls under health tourism which is a subset of tourism studies. Accordingly, tourism pertains to the interdisciplinary between the interaction of tourists, business suppliers, governments, communities and environment which falls under the human behavioural studies. As Setyowati, Harani, and Falah (2013) puts it, health and behaviour are interconnected as it integrates various department and functions as well as serves patients from a differing background. On the other hand, health tourism is commonly known as travelling across one's country borders for one's mental and physical wellbeing. Thus, medical tourism relates to the travel of people who are in search of medical treatments as their main intention of the trip.

Meanwhile, Nielsen et al. (2017) put forward that there is no single definition, cause and theoretical framework on sexual harassment, hence the definition of such misconduct is worth to look into. According to Malaysia's Code of Practice on the Prevention and Eradication of Sexual Harassment, sexual harassment is defined as unwanted conduct of sexual nature has the effect of verbal, non-verbal, visual, psychological or physical harassment. The Code of Practice also explained that verbal harassment comes in the forms of offensive or suggestive remarks, non-verbal harassments occur through leering or ogling with suggestive overtones. On the

eISSN: 2398-4287C 2018. The Authors. Published for AMER ABRA cE-Bsby e-International Publishing House, Ltd., UK. This is an open access article under the CC BYNC-ND license (http://creativecommons.org/licenses/by-nc-nd/4.0/). Peer-review under responsibility of AMER (Association of Malaysian Environment-Behaviour Researchers), ABRA (Association of Behavioural Researchers on Asians) and cE-Bs (Centre for Environment-Behaviour Studies), Faculty of Architecture, Planning \& Surveying, Universiti Teknologi MARA, Malaysia.

DOI: https://doi.org/10.21834/e-bpj.v3i8.1390 
other hand, visual harassment means that showing pornographic materials-based letters or sexual exposure, while psychological harassment could happen through repeated insistent and unwanted social invitations. Finally, physical harassment means the occurrence of inappropriate touching.

Meanwhile, Small-Medium Enterprise (SME) healthcare facilities carry different meanings due to the differing methods of classification. While some authors posit that the size of healthcare facilities depend on the number of bed, some others would define it based on electricity usage. For instance, for inpatient-based healthcare facilities, centres with 200 or less bed are deemed small, while medium facilities are those that range between 201 and 600 beds, and big facilities are those with over 600 beds (Ahmed, Rajagopalan, \& Fuller, 2015). Non-patient services such as clinic, medical centres ambulatory services and dentists are deemed to be small healthcare facilities (Ahmed et al., 2015). Hence, it is seen that small and medium-sized healthcare facilities are not only confined to hospitals but also include clinics, spas and dental clinics as medical checkups.

\subsection{Literature Review}

\subsection{An Overview of Sexual Harassment on Medical Practitioners in SME Healthcare}

Although sexual harassment is prevalent in many circumstances, medical practitioners are also more exposed to such misconduct due to their work nature that requires close proximity to patients. Among the frequently recorded types of harassments are improperly touching the physicians during a psychical examination, genital disclosure, excessively discussing sexual matters and several uncomforting behaviours such as eradication during physical examinations. Moreover, sexual harassment in the healthcare industry, as a whole, has been prevailing for decades that affect a wide range of medical practitioners. For instance, Lee, Song, and Kim (2011) posited that over 52 percent of 542 female Korean nursing students had experienced at least one type of sexual harassment during their clinical practice. The perpetrators are mostly male patients in their 40 s with whereby the majority of them are in the psychiatric ward.

As the menace of non-fatal violence at the workplace is 16 times more apparent for healthcare practitioners than that for other sectors (Boissonnault, Cambier, Hetzel, \& Plack, 2017), sexually-related patients' behaviours towards therapist are also prevalent. This is unveiled through an electronic survey of 890 physical therapists; professionals and students. In which, it is found that the risk of being sexually harassed is relatively high on practitioners with less working experience on direct contact with patients, working with cognitively impaired patients routinely, female practitioners are also exposed to the risk when dealing with male patients. Further, there are three major categories unveiled to be explaining the situation of such misbehaviour towards therapists. The first is 'patient-related characteristics'such types of diagnosis, age and gender whereby neurologically impaired older patients are prominently behaving inappropriately. Meanwhile, the second criteria that were unravelled were medical practitioners' personal and professional characteristics which considered age, gender, marital status, treatment types and experience in providing care. Hence, Boissonnault et al. (2017) unveiled that young and single female therapists with less working experience are prone to experiencing the inappropriate behaviour towards them. The final criteria for explaining sexual harassment is the specific abusive actions or events. In this aspect, inappropriate conversation, flirting jokes and stalking are among the reported cases of harassment that therapist went through during their working hours.

Meanwhile, sexual harassment in Malaysian healthcare settings is as equally prevalent. Through 108 questionnaires from clinical and non-clinical medical staff at Hospital Kuala Lumpur (HKL), it is found that over $40 \%$ of them are exposed to sexually-related misbehaviour from patients. Contradicting with Boissonnault et al. (2017), the results from Yusop, Dempster, and Stevenson (2014) unveiled that occurrence of harassment does not differ between employees' grade and position. Yusop et al. (2014) also found that harassment, which also constitutes sexual, is topmost experience inappropriate followed by bullying and mobbing. While findings on the private healthcare settings and SME healthcare facilities in Malaysia are scarce, the extant arguments should stand as a strong argument on the prevalence of sexual harassment in SME healthcare facilities thus justifying the needs for corrective actions in shaping the behaviour of the practitioners and patients.

\subsection{An Overview of Sexual Harassment on Patients in SME Healthcare}

In July 2017, a female patient in her mid-20s who went for treatment at Jesselton Medical Centre, Kota Kinabalu claimed the doctor who was treating her was behaving unethically (Roslan, 2018). Although the patient herself withdrew the claim, this should serve the needs to have a sound policy on sexual harassment that would shape the behaviour of patients should they come across such situation. Moreover, a suspected sexual harassment by a male nurse on a female sedated patient (Tempo.Co, 2018) in Surabaya was also reported in January 2018. In the United States, a former in Mt Sinai Emergency Room was charged with first- and four-degree sexual abuses on four female patients. Among the apparent allegations was that the doctor masturbated on the patient after putting her on sedation despite having been told that nurses had already done the procedures (Mueller, 2016). Through reports made the victims and investigation by the authoritative bodies, DNA evidence found on her was has proven that the doctor was guilty and later being sued.

Findings on cases for Malaysian patients being victimised is scarce, and the same is for medical tourist in this country. Nevertheless, this should not negate the severity of sexual harassment at healthcare and let alone in the SME settings. The scarce findings may reflect underreporting of sexual harassment could be due to several reasons such as cultural sensitivity or fear of reporting (Fallahi-Khoshknab et al., 2015). Nevertheless, the establishment of the One Stop Crisis Centre: Policy and Guidelines for 
Hospitals by Ministry of Health Malaysia that delineates the hospital procedures in handling public sexual harassment and assaults, should serve as an indicator that of the occurrence of sexual harassment on public and patients at healthcare facility specifically.

\subsection{Sensitivity of Medical Tourists and Medical Practitioners on the Issue of Sexual Harassment}

Although sexual harassment cases may not be apparent in the medical tourism industry as at present, that should not excuse the medical tourists and medical practitioners from considering this issue prior to choosing a destination location or employment within the industry. To ensure a safe medical tourism experience, medical tourists should strongly consider the physical and psychological risks that the healthcare facilities and physician may impose towards them, including sexual harassment. Nevertheless, extant literature unveils that potential medical tourists are rather interested in the treatments specialties, interpersonal communication with the medical practitioners and treatment costs creating a prominent gap on specific issues in sexual harassment. For instance, 354 cosmetic medical tourists in Korea posited that outcome fairness which constitutes that cognitive, affective and behavioural output that they receive from undergoing the treatment should be similar to the comparable others (Um \& Kim, 2018). Failure to achieve the expectation would lead to their dissatisfaction. Apart from that, medical tourists also have tendencies to behave in certain ways such as, switching to other country or healthcare facilities or deliver the negative word of mouth, if they are unsatisfied with the process and procedures of treatments as well as the interaction and attention provided to them.

Similarly, treatment costs are among the highest scored reasons for medical tourists to seek for treatments abroad. This usually means to say that patients' local healthcare costs are high that they would want to go for alternative options in foreign countries with more affordable fees. Nevertheless, patients in Bangladesh are found to seek for treatments in Indiadue to the perceived quality of services that healthcare facilities there offer although the cost is not as efficient as in their home country (Mamun \& Andaleeb, 2013). Specifically, the Bangladeshi are keen to experience the accredited healthcare facilities in India that has excellent technology, medical practitioners' competencies and great patient engagement. The movements of patients from local healthcare services are due to that the domestic healthcare service providers are usually more anxious about their costs instead of their service quality (Mamun \& Andaleeb, 2013). Although reports have been lodged about their services, Mamun and Andaleeb (2013) asserted that improvements have yet to be seen.

Thus, it can be said that from medical tourists' perspectives, their decision to choose a destination country is normally based on accreditation of the healthcare facility, medical practitioners' competencies, affordable costs, shorter waiting time, and the overall service quality in the medical tourism experience. Although Radmanesh (2016) conjectured that patients are also concerned about the risk associated with being in the foreign country, his findings do not emphasise on the safety risk of being exposed to sexual harassment per se. Instead, Radmanesh (2016) conceived that potential medical tourists are more anxious about the risks of malpractice law, accreditation, side effects of treatments, infection. This also suggests that medical tourists possess low awareness on sexual harassment at healthcare facilities that this aspect is not included in their decision-making model. While the local patients in a country may be experiencing sexual harassments, it should be regarded as another important safety aspect for potential medical tourists to look for prior to making decisions on the destination country and healthcare facilities to undergo their treatments.

Meanwhile, medical practitioners' motives for choosing a healthcare facility vary between gender, working sector and specialty. Hence, several aspects that stand as the motives for the choice of a workplace are; good workplace, career and professional progress, non-work related issues, personal contact and salary (Heikkilä et al., 2014). A good workplace would mean that the environment provides supportive colleagues and superiors. Meanwhile, career and professional progress constitute aspects of the medical practitioners' career path. On the other hand, non-work related issues pertain to concerns that are outside of working life and personal contact delineates previous contacts with the superior and the medical practitioners' personal reputation. A random survey of licensed 7758 medical practitioners between 1977 and 2006 in Finland was conducted to get their perspectives on the aspects that drive them to choose to the workplace. Accordingly, the motives are as delineated before. Nevertheless, it is also important to note that elder medical practitioners are less interested in good workplace, career and professional progress and non-work related issues. Meanwhile, female practitioners are inclined towards non-work related issues and career progress that a healthcare facility offers.

Similarly, searching for better work condition and career progress are among the top factors for medical practitioners to choose a workplace (Ribeiro et al., 2014). In detail, medical practitioners, such as those from Africa and East Europe choose Portugal as a workplace due to the availability of new types of equipment, protective devices and diagnosis tools, low occupational risks such as viruses and epidermis and improved salaries. Apart from that, better workload, non-work related remuneration and availability of employment opportunities are the driving force for selecting a new workplace beyond the Portugal borders. Therefore, it is seen that the movement of medical practitioners across national borders are due to improved financial and non-financial work condition. Nevertheless, the choice of safety as one of the decision factors to choosing a workplace has not found to be the prominent reason. Similar to medical tourists, medical practitioners seeking employment abroad can also be inferred as having low awareness on the safety measures, specifically the sexual harassment issues, in their potential workplace. While the existing local medical practitioners may already be experiencing sexual harassment, as prominently described in the previous section, this issue should be taken into account as one of the risks associated with working abroad should foreign medical practitioners wish to enter a foreign healthcare environment. Psychological, along with the economic and social aspect of work and life should be well integrated to produce a wellbalanced economic development of a country, especially in Malaysia (Bakar, Osman, Bachok, \& Ibrahim, 2016). 


\subsection{Methodology}

Studies of human behaviour in the healthcare facility are essential considering the dynamic roles of medical practitioners and diversified background of the patients (Setyowati et al., 2013). Therefore, the medical tourism industry is liable to ensure that grievances mechanism is laid before the employees and patients in shaping their appropriate behaviour, which this paper is deemed to reciprocate to. With the thoughts on the prevailing sexual harassments presented, this article delineates on the behaviour of medical practitioners and patients in Malaysia's healthcare settings specifically the medical tourism industry. Through analysis from journal articles, reports and newspaper articles, the present literature review discusses on the behaviour of medical practitioners and patients as the perpetrators and victims of sexual harassment, as well as the means of handling the situation. Specifically, articles are selected based on several keywords such as "sexual harassment", "healthcare", "medical tourism" and "grievance mechanism". Emphasis is placed on publications between 2012 and 2018. Nevertheless, the present paper lacks primary data which serves as a new direction for future research to extend the arguments with evidence from empirical findings. Apart from that, this paper also provides insufficient reviews on publications prior to the mentioned years resulting in the lack of coverage on the pioneers' perspectives on the behaviour of medical practitioners and medical tourists towards sexual harassment.

\subsection{Discussion}

\subsection{Medical Practitioners' and Patients' Response towards Sexual Harassment}

Based on the cases of sexual harassment, it is seen that women are prone to be sexually harassed as opposed to men. Female victims experience stronger effects from the misbehaviour which is partially due to them being reluctant to lodge a report (Zain, 2012). From healthcare settings, such misbehaviour adversely affecting medical practitioners' work performance such as causing headache, reduced workability, alcohol consumption and self-reported stress (Friborg et al., 2017). Although Friborg et al. (2017) revealed that sexual harassment by colleagues leads to a more pervasive depressive symptom than that by patients, this concern needs an urgent precautionary and corrective action because the symptoms are more prevalent to sexually harassed medical practitioners than those who did not experience it. Apart from that, medical practitioners are also afraid (Nielsen et al., 2017) and in fact have been charged with retaliation and marginalisation(Jagsi, 2018) when they bring their report to external authority such as police which undermines their power to stand up. The undesirable situations that these medical practitioners have to undergo results in many of them leaving the workforce due to the continuity of the unbearable experience(Nielsen et al., 2017).

Furthermore, female victims' reluctance to take the necessary actions against the victimisation is due to several reasons such as lower hierarchy in the organisation, lack of recognition on the job and task they perform, and a lesser degree of autonomy and decision-making in their workplace (Zain, 2012). Through normalisation, medical practitioners are also told to merely accept the mishap instead taking corrective actions because those are part of what their job entails(Friborg et al., 2017; Nielsen et al., 2017) This is especially considering that the perpetrators are patients with cognitive disparity. Consequently, it results in the practitioners ignoring the harassment (Boissonnault et al., 2017), verbally prohibit the patients from continuing the misbehaviour and report to colleagues and supervisors(Friborg et al., 2017; Nielsen et al., 2017). The absence of an explicit sexual harassment policy also hinders them from stepping up for themselves because they view reporting as fruitless (Fallahi-Khoshknab et al., 2016)since there is no sound channel to advance their concern and implement the supposed corrective actions (Friborg et al., 2017; Nielsen et al., 2017)

As for patients, it also important to note that local patients are given the access and time to lodge a police report and take the necessary legal actions moving forward. That being said, it is also complicated to channel the concern due to the absence of a sexual harassment policy at the national and firm level that would have made it more transparent for the victims to take their legal actions.

Nevertheless, such actions are deemed privilege for medical tourists due to their short stay in the destination country. Medical tourists may not have the ample time to go through the necessary procedures should they encounter similar experience due to their physical constraints of being under treatment, limited visa period, and low know-how of a country's lodging procedures. This is also supported by Radmanesh (2016) who, through his qualitative interview, found that medical tourists consider legal risk as one of their decision-making factors. This constitutes understanding the do's and don'ts in the country, as well as in case of emergencies. Being unfamiliar with the legal system in the destination country would hinder medical tourists from going for their treatments there because it impedes their efforts to take legal actions to back themselves up should they experience any mishap. Therefore, the present situation also signifies the needs for a sexual harassment policy that could be easily taken as guidelines in protecting both, the medical practitioners and patients especially in the SME settings which proper task segregations are deemed poor due to the small number of workforce.

\subsection{Strategies for Precautionary and Corrective Actions to Sexual Harassment}

As responsible tourism leads to improved life quality (Hanafiah, Azman, Jamaluddin, \& Aminuddin, 2016), attention should be made to cater for both the service providers and medical tourists. While medical practitioners are perturbed by the limited means of bringing their complaint forward, the top management of SME healthcare facilities is urged to provide a platform to address this concern, since the provision of adequate facilities is essential to the local workforce (Fachrudin \& Lubis, 2016). This is due to leader trust, colleague support and organisational justice should also be taken into considerations because they determine the formation of the intention to report, which when combined with behaviour control, would affect employees' actual reporting behaviour (Clarke, 2014). Healthcare practitioners' needs are just as critical to be taken care of (Kamali \& Abbas, 2012). Therefore, support and shielding to the employees 
are needed. This can come through sending more experienced practitioners to handle problematic patients, counselling sessions to assist their emotional burden of managing the circumstances and job rotation (Nielsen et al., 2017).

Nevertheless, these measures are perceived as temporary because the significant number of patients barricades the exercise of shielding since there is a scarcity of medical practitioners in the healthcare facility. Although employees' self-initiative is the prominent predictor to their reporting behaviour, the importance of healthcare workers having an accommodating environment that entertains their reports on sexual harassment by both the patients and staff is as equally important. The healthcare environment is not only important to patients satisfaction level (Ghazali \& Abbas, 2012) but also the medical practitioners' workplace conduciveness (Kamali \& Abbas, 2012). This calls for appropriate management strategy (Rani, Baharum, Akbar, \& Nawawi, 2015) to prevent and eradicate sexual harassment at harassment healthcare facilities thus ensuring a healthy environment for its occupants.

Due to the psychological effects of sexual harassment on victims, it is essential SME healthcare centres to provide a mental safe healthcare environment such as providing a sound sexual harassment policy that caters for both patients and staff. While these stakeholders have differing interest in the organisation thus requiring unique needs, a transparent process flow of avoiding, mediating, correcting and/or transferring to higher authority should be laid before them. Moreover, these stakeholders should also be informed about their rights through various means. For instance, training for employees should be conducted on a timely basis(Lee et al., 2011) instead of being treated as an annual program because methods of exposure and training frequency are the elements for useful sexual harassment training outcome.

Meanwhile, patients should also be informed about the ways of reporting sexual harassment through posters, information boards and audio-visual devices that are available at the healthcare facility. As patients and their families place high hopes for medical practitioners in improving their health (Hashim \& Hussin, 2012), their trust to the service providers must be taken seriously. Briefing on such is also essential at the beginning of their treatments or stay at the centre. Apart from that, they should also be briefed on the responsibilities of medical practitioners (Fallahi-Khoshknab et al., 2016)that practise close contact with them as procedures of physical examination. Nevertheless, patients should have the awareness that they have the rights to speak up when they feel that the physician has crossed the border. Furthermore, understanding the preference and behaviour of medical tourists are essential (Mohit, 2014). Since medical tourist emphasised on health travels with minimised risk (Radmanesh, 2016), it would shape their behaviour in choosing a destination country and healthcare facility.

As lack of security forces is one of the most contributing factors to sexual harassment at healthcare facilities (Fallahi-Khoshknab et al., 2015), service providers need to always escalate on the safety measures of their services (Othman, Jaafar, Harun, \& Ibrahim, 2015). Safety measure and security forces can come in many ways such as installing closed circuit television (CCTV) at every corner of the premise, having more than one security guard at a time, improve the lighting and provide more access to exit the premise. Functioning premises is deemed essential to the physical improvements of healthcare facilities(Almhafdy, Ibrahim, Ahmad, \& Yahya, 2013; Samah, Ibrahim, \& Amir, 2013). Moreover, the available panic button that is usually given to patients at wards can be advanced to serve the purpose of reporting. Since it is already helping patients at hospitals, SME healthcare facilities could provide a cordless panic button to patients should they need assistance from any mishap especially sexual harassment.

Similarly, the button could also serve for the medical practitioners considering that patients and treatment rooms are secluded thus hindering their escape plans. Although the idea might seem absurd, it is already waiting to be implemented at hotels in Chicago, United States. The Chicago City Council passed an amended Section 4-6-180 f(1)under the Municipal Code requiring hotels, as their legal duties, to give a panic button to hotel workers, union or non-union, the housekeepers and other staff who might work alone in a hotel room and realised that they are in trouble. This section will take effect on 1 st July 2018. Hence, the alarm button would alert the security if the hotel workers need help should they find themselves in trouble from the guests' sexual harassment or assault.

\subsection{Conclusion}

Therefore, the conceptual article has delineated the severity of sexual harassment in healthcare setting about both medical practitioners and patients. While young, female, less experienced and low-hierarchy practitioners are found to be more at risk of sexual harassment at workplace, similar instances are located on patient too. Consequences such as depressive symptoms, low job performance, burnout and employees leaving the workforce resemble the profound need for corrective actions to protect the workforce in the healthcare industry. Similarly, patients are also found to suffer from psychological effects of sexual harassments. Adding to the severity, low-level work hierarchy, as well as the absence of clear policy and guidelines, hamper the medical practitioners and patients to channel their complaints thus leaving the cases unattended. As for medical tourists, the present article conceptualises that low know-how of lodging a report and the time constraints as due to their short tourism visa could be the hindering factor for bringing their case to higher authority.

Also, the present paper reveals the lack of findings on sexual harassment in the medical tourism industry which could be due to cultural sensitivity, fear of reporting. This suggests for future scholars to empirically research on their experiences, perceptions and suggested corrective actions on avoiding and correcting sexual harassment in Malaysia. Finally, this article is deemed essential to address the present situation of sexual harassment in the healthcare industry and the potential risk that SME healthcare and medical tourist hold, which directs theirbehaviour to prepare for the necessary before they encounter sexual harassment in the medical tourism industry. As long as the medical practitioners and medical tourists having low awareness of sexual harassment, the occurrence of sexual harassment will continue to happen thus affecting the growth of medical tourism industry in the long run. Therefore, there is also a strong role for the media and medical tourism councils to increase awareness of the medical tourists and medical practitioners on the imminent issue of sexual harassment so that the message can be delivered in mass volume. 


\section{Acknowledgement}

The authors would like to thank the Ministry of Higher Education Malaysia for the financial support through the Fundamental Research Grant Scheme (FRGS), File No: 600-RMI/FRGS 5/3 (36/2015) and the Research Management Centre, Institute of Research Management \& Innovation (IRMI) Universiti Teknologi MARA, Shah Alam for managing the fund.

\section{References}

Ahmed, T. M. F., Rajagopalan, P., \& Fuller, R. (2015). A Classification of Healthcare Facilities:Toward the Development of Energy Performance Benchmarks for Day Surgery Centers in Australia. HERD: Health Environments Research \& Design Journal, 8(4), 139-157. doi:10.1177/1937586715575910

Almhafdy, A., Ibrahim, N., Ahmad, S. S., \& Yahya, J. (2013). Analysis of the Courtyard Functions and its Design Variants in the Malaysian Hospitals. Procedia - Social and Behavioral Sciences, 105, 171-182. doi:https://doi.org/10.1016/j.sbspro.2013.11.018

Azmi, E., \& Ismail, M. Z. (2016). Cultural Heritage Tourism: Kapitan Keling Mosque as a Focal Point \& Symbolic Identity for Indian Muslim in Penang. Procedia - Social and Behavioral Sciences, 222, 528-538. doi:https://doi.org/10.1016/j.sbspro.2016.05.211

Bakar, A. A., Osman, M. M., Bachok, S., \& Ibrahim, M. (2016). Investigating Rationales of Malaysia Quality of Life and Wellbeing Components and Indicators. Procedia - Social and Behavioral Sciences, 222, 132-142. doi:https://doi.org/10.1016/j.sbspro.2016.05.202

Boissonnault, J. S., Cambier, Z., Hetzel, S. J., \& Plack, M. M. (2017). Prevalence and Risk of Inappropriate Sexual Behavior of Patients Toward Physical Therapist Clinicians and Students in the United States. Physical Therapy, 97(11), 1084-1093. doi:10.1093/ptj/pzx086

Clarke, H. M. (2014). Predicting the decision to report sexual harassment: Organizational influences and the theory of planned behavior. Journal of Organizational Psychology, 14(2), 52-65.

Fachrudin, H. T., \& Lubis, M. D. (2016). Planning for Riverside Area as Water Tourism Destination to Improve Quality of Life Local Residents, Case Study: Batuan Sikambing River, Medan, Indonesia. Procedia - Social and Behavioral Sciences, 234, 434-441. doi:https://doi.org/10.1016/j.sbspro.2016.10.261

Fallahi-Khoshknab, M., Oskouie, F., Ghazanfari, N., Najafi, F., Tamizi, Z., \& Afshani, S. (2016). Physical violence against health care workers: A nationwide study from Iran. Iran J Nurs Midwifery Res., 21(3), 232-238.

Fallahi-Khoshknab, M., Oskouie, F., Ghazanfari, N., Najafi, F., Tamizi, Z., Afshani, S., \& Azadi, G. (2015). The Frequency, Contributing and Preventive Factors of Harassment towards Health Professionals in Iran. International Journal of Community Based Nursing and Midwifery, 3(3), 156-164.

Friborg, M. K., Hansen, J. V., Aldrich, P. T., Folker, A. P., Kjær, S., Nielsen, M. B. D., . . Madsen, I. E. H. (2017). Workplace sexual harassment and depressive symptoms: a cross-sectional multilevel analysis comparing harassment from clients or customers to harassment from other employees amongst 7603 Danish employees from 1041 organizations. BMC Public Health, 17(1), 675. doi:10.1186/s12889-017-4669-x

Ghazali, R., \& Abbas, M. Y. (2012). Newly Built Public Paediatric Wards Increase Length of Stay (LOS)? In M. Y. Abbas, A. F. I. Bajunid, \& N. F. N. Azhari (Eds.), AceBs 2012 Bangkok (Vol. 50, pp. 623-632). Amsterdam: Elsevier Science Bv.

Hanafiah, M. H., Azman, I., Jamaluddin, M. R., \& Aminuddin, N. (2016). Responsible Tourism Practices and Quality of Life: Perspective of Langkawi Island communities. In M. Y. Abbas, A. F. I. Bajunid, \& S. Thani (Eds.), Asean-Turkey Asli Qol2015: Aicqol2015 (Vol. 222, pp. 406-413).

Hashim, F., \& Hussin, R. (2012). Family Needs of Patient Admitted to Intensive Care Unit in a Public Hospital. In M. Y. Abbas, A. F. I. Bajunid, \& N. F. N. Azhari (Eds.), Asean Conference on Environment-Behaviour Studies (Vol. 36, pp. 103-111). Amsterdam: Elsevier Science Bv.

Heikkilä, T. J., Hyppölä, H., Aine, T., Halila, H., Vänskä, J., Kujala, S., . . Mattila, K. (2014). How do doctors choose where they want to work? - Motives for choice of current workplace among physicians registered in Finland 1977-2006. Health Policy, 114(2), 109-117. doi:https://doi.org/10.1016/j.healthpol.2013.12.001

Jagsi, R. (2018). Sexual harassment in medicine— \# MeToo. New England Journal of Medicine, 378(3), 209-211.

Kamali, N. J., \& Abbas, M. Y. (2012). Healing Environment: Enhancing Nurses' Performance through Proper Lighting Design. Procedia - Social and Behavioral Sciences, 35, 205-212. doi:https://doi.org/10.1016/j.sbspro.2012.02.080

Lee, S.-K., Song, J.-E., \& Kim, S. (2011). Experience and Perception of Sexual Harassment During the Clinical Practice of Korean Nursing Students. Asian Nursing Research, 5(3), 170-176. doi:https://doi.org/10.1016/j.anr.2011.09.003

Mamun, M. Z., \& Andaleeb, S. S. (2013). Prospects and problems of medical tourism in Bangladesh. International Journal of Health Services, 43(1), $123-141$.

Mohit, M. A. (2014). iPresent Trends and Future Directions of Quality-of-Life. Procedia - Social and Behavioral Sciences, 153, $655-665$. doi:https://doi.org/10.1016/j.sbspro.2014.10.097

Mueller, B. (2016). E.R. Doctor at Mt. Sinai Hospital Charged With Sexual Abuse of 2 Patients. New York Times. Retrieved from https://www.nytimes.com/2016/01/20/nyregion/er-doctor-at-mt-sinai-hospital-charged-with-sexual-abuse-of-2-patients.html

Nielsen, M. B. D., Kjær, S., Aldrich, P. T., Madsen, I. E. H., Friborg, M. K., Rugulies, R., \& Folker, A. P. (2017). Sexual harassment in care work - Dilemmas and consequences: A qualitative investigation. International Journal of Nursing Studies, 70, 122-130. doi:https://doi.org/10.1016/j.jnurstu.2017.02.018

Othman, N. L., Jaafar, M., Harun, W. M. W., \& Ibrahim, F. (2015). A Case Study on Moisture Problems and Building Defects. In M. Y. Abbas (Ed.), Asian Conference on Environment-Behaviour Studies (Vol. 170, pp. 27-36).

Radmanesh, A. (2016). A Case Study of the Decision Model for American Outbound Medical Tourists. Graduate Faculty of St. Cloud State University. 
Rani, N. A. A., Baharum, M. R., Akbar, A. R. N., \& Nawawi, A. H. (2015). Perception of Maintenance Management Strategy on Healthcare Facilities. Procedia - Social and Behavioral Sciences, 170, 272-281. doi:https://doi.org/10.1016/j.sbspro.2015.01.037

Ribeiro, J. S., Conceição, C., Pereira, J., Leone, C., Mendonça, P., Temido, M., . . Dussault, G. (2014). Health professionals moving to... and from Portugal. Health Policy, 114(2), 97-108. doi:https://doi.org/10.1016/j.healthpol.2013.05.009

Roslan, F. (2018). Alleged sexual harassment victim clears doctor's name. Borneo Post. Retrieved from http://www.theborneopost.com/2018/02/08/alleged-sexualharassment-victim-clears-doctors-name/

Samah, Z. A., Ibrahim, N., \& Amir, J. S. (2013). Translating Quality Care Factors to Quality Space: Design Criteria for Outpatient Facility. Procedia - Social and Behavioral Sciences, 105, 265-272. doi:https://doi.org/10.1016/j.sbspro.2013.11.028

Setyowati, E., Harani, A. R., \& Falah, Y. N. (2013). Green Building Design Concepts of Healthcare Facilities on the Orthopedic Hospital in the Tropics. In M. Y. Abbas (Ed.), Amer (Vol. 101, pp. 189-199). Amsterdam: Elsevier Science Bv.

Tempo.Co. (2018). Molestation in National Hospital Allegedly Due to Nurse's Mistake. Tempo.Co. Retrieved from https://en.tempo.co/read/news/2018/01/27/055915211,uk.htm//Molestation-in-National-Hospital-Allegedly-Due-to-Nurses-Mistake

Um, K.-H., \& Kim, S.-M. (2018). Application of Fairness Theory to Medical Tourists' Dissatisfaction and Complaint Behaviors: The Moderating Role of Patient Participation in Medical Tourism. Journal of Social Service Research, 44(2), 191-208.

Yusop, Y. M., Dempster, M., \& Stevenson, C. (2014). Understanding Inappropriate Behaviour: Harassment, Bullying and Mobbing at Work in Malaysia. Procedia Social and Behavioral Sciences, 127, 179-183. doi:https://doi.org/10.1016/j.sbspro.2014.03.236

Zain, Z. M. (2012). The Awareness on Gender-based Violence among Students in the Higher Learning Institutions. Procedia - Social and Behavioral Sciences, $38,132-$ 140. doi:https://doi.org/10.1016/j.sbspro.2012.03.333 